\title{
Evaluasi Tata Letak Gedung Perpustakaan dengan Jumlah Pengunjung Studi Kasus pada Perpustakaan Sekolah SD Negeri Glagahombo 1
}

\author{
Dwi Wahyu Utami \\ Perpustakaan SD Negeri Glagahombo 1 \\ email:wieutamy123@gmail.com
}

\begin{abstract}
Abstrak
Keberadaan perpustakaan sekolah sebagai pendukung kegiatan belajar mengajar di sekolah tidak dapat kita kesampingkan. Dalam perencanaan pembangunan gedung hendaknya memperhatikan berbagai kriteria agar perpustakaan bisa berjalan dengan optimal. Tata letak gedung perpustakaan akan sangat berpengaruh dengan rasio tingkat pengunjung. Gedung perpustakaan yang terlalu jauh dan tidak menarik akan menjadikan pengunjung malas untuk berkunjung dan tidak tertarik pada perpustakaan itu sendiri. Gedung perpustakaan yang baik hendaknya berada di lingkungan pusat kegiatan peserta didik, mudah dijangkau dan berada pada pada lingkungan yang aman dan nyaman. Selain itu, desain ruang perpustakaan juga harus dirancang secara khusus agar dapat menjadi magnet tersendiri bagi pengunjung. Penelitian ini bertujuan untuk mengetahui adanya pengaruh tata letak gedung perpustakaan dengan jumlah pengunjung perpustakaan. Penelitian ini menggunakan metode kualitatif dengan teknik pengumpulan data melalui pengamatan/observasi dan wawancara. Hasil penelitian ini diharapkan mampu menjadi evaluasi agar perpustakaan dapat berjalan seiring dengan tujuan yang ingin dicapainya. Dari hasil penelitian yang diperoleh di lapangan, perpustakaan sekolah di SD Negeri Glagahombo 1 belum berjalan dengan baik yang diakibatkan oleh beberapa faktor yang salah satunya adalah keberadaan perpustakaan yang terlalu jauh dari pusat kegiatan menjadikan peserta didik malas berkunjung ke perpustakaan
\end{abstract}

\section{Kata Kunci:}

perpustakaan sekolah gedung perpustakaan tata letak gedung

\section{A. PENDAHULUAN}

Pada zaman informasi dan globalisasi ini, informasi berkembang semakin banyak. Informasi menjadi suatu kebutuhan yang harus terpenuhi agar wawasan dan pengetahuan menjadi bertambah luas sehingga mampu mengikuti perkembangan zaman. Perpustakaan sebagai sarana penyedia informasi dan pelestarian kebudayaan, mempunyai peranan yang sangat penting untuk keperluan pendidikan, penelitian, dan pengembangan ilmu pengetahuan. Penelususran informasi yang tepat dan sesuai dengan kebutuhan pemustaka akan sangat membantu pemustaka dalam mendapatkan informasi yang dibutuhkan (Basuki, 2010)

Keberadaan perpustakaan merupakan elemen penting dalam dunia pendidikan. Untukmendukung gerakan literasi dan minat baca yang digalakkan pemerintah, tentunya peran perpustakaan sebagai pendukung kegiatan belajar mengajar tidak dapat kita kesampingkan. Maka dari itu tata letak gedung dan segala sarana dan prasarananya perlu kita perhatikan.

Tata letak gedung perpustakaan hendaknya memperhatikan jarak dan kenyamanan. Letak gedung yang terlalu jauh dengan pusat kegiatan akan berpengaruh terhadap jumlah pengunjung perpustakaan. Selain itu, faktor kenyamanan juga menjadai salah satu faktor yang penting karena ruang perpustakaan yang nyaman akan mempengaruhi betah atau tidaknya pemustaka 
berkunjung ke perpustakaan.

Pada penelitian kali ini penulis melakukan penelitian terhadap tata letak Gedung Perpustakaan Sekolah di SD Negeri Glagahombo 1. Dalam menjalankan fungsinya perpustakaan tidak hanya mengandalkan koleksi saja, karena jika koleksi tidak dimanfaatkan tidak akan dapat dirasakan manfaatnya. Maka dari itu, perpustakaan seharusnya mempunyai cara tersendiri agar dapat menarik pengunjung agar koleksi dapat dimanfaatkan secara maksimal.

Dari data yang penulis peroleh, penulis mengidentifikasi masalah dalam penilitian ini adalah :

1. Mengapa perpustakaan sekolah belum dipergunakan secara maksimal oleh seluruh peserta didik?

2. Apa saja kendala yang dialami sekolah dalam mengembangkan perpustakaan?

\section{B. METODE PENELITIAN}

Dalam menyusun laporan ini, tentunya penulis harus menggunakan beberapa metode penelitian. Adapun metode yang digunakan penulis adalah metode kualitatif dengan teknik pengumpulan data melalui pengamatan/ observasi dan wawancara. Metode penelitian kualitatif merupakan penelitian yang berhubungan dengan data nonnumerik, dalam mendiskripsikan prosedur-prosedur sering menggunakan narasi. Sebagian besar tidak menggunakan metode statistik dalam membuat kesimpulan, analisa data hanya menggunakan statistik deskriptif (Hartinah, 2014).

Teknik pengumpulan data observasi adalah kegiatan pengumpulan data dengan melihat langsung kegiatan responden tanpa interaksi langsung dengan responden (Hartinah, 2014). Observasi dilakukan dengan cara observasi tanpa intervensi, hanya mencatat objek yang diobservasikan apa adanya ketika perilaku objek yang diamati akan terlihat secara normal.
Sedangkan teknik pengumpulan data wawancara adalah kegiatan pengumpulan data dengan menggunakan panduan/pedoman wawancara yang berisi beberapa pertanyaan tentang masalah yang diteliti kepada responden (Hartinah, 2014). Dalam hal ini, penulis melakukan wawancara terhadap petugas perpustakaan sekolah. Kegiatan wawancara ini dilakukan untuk menggali informasi lebih dalam lagi mengenai perpustakaan sekolah.

\section{HASIL PEMBAHASAN}

Gedung/ruangan perpustakaan merupakan sarana penting dalam penyelenggaraan perpustakaan. Gedung perpustakaan sekolah SD Negeri Glagahombo 1 berdiri pada tahun 2005 dengan luas $56 \mathrm{~m}^{2}$. Biaya pembangunan gedung ini berasal dari Dana Alokasi Khusus (DAK) APBD kabupaten Sleman. Bangunan gedung ini terlihat sederhana sekali, tidak jauh beda dengan ruangruang lain yang digunakan untuk pembelajaran.

Perpustakaan sekolah SD Negeri Glagahombo 1 yang diberi nama Perpustakaan "Padmanaba" ini belum menjalankan fungsinya secara maksimal. Pengelola perpustakaan yang diberikan pekerjaan lain selain tugasnya sebagai pengelola perpustakaan adalah penyebab utama perpustakaan agak terbengkalai. Ini seharusnya menjadi perhatian khusus pemimpin sekolah dalam membagi tugas guru dan stafnya.

Gedung perpustakaan sekolah SD Negeri Glagahombo 1 berada di belakang gedung utama dan jauh dari jangkauan peserta didik. Hal ini akan sangat berpengaruh dengan tujuan yang ingin dicapai oleh perpustakaan yaitu meningkatkan jumlah pengunjung perpustakaan dan meningkatkan minat baca peserta didik. Jarak perpustakaan yang agak terlalu jauh dari pusat kegiatan peserta didik ini menjadi salah satu penyebab anak-anak malas berkunjung ke perpustakaan. Dalam penentuan lokasi gedung 
Evaluasi Tata Letak Gedung Perpustakaan dengan Jumlah Pengunjung Studi Kasus pada Perpustakaan Sekolah SD Negeri Glagahombo 1 D. W. Utami

perpustakaan sekolah hendaknya memperhatikan beberapa kriteria diantaranya : berada di sekitar pusat kegiatan peserta didik, mudah dicapai oleh peserta didik, dan berada di kawasan yang cukup tenang dan aman.

Sekolah ini juga menerapkan gerakan literasi sekolah. Gerakan literasi ini dilakukan 15 menit sebelum pembelajaran dimulai. Dari pengamatan penulis, seluruh peserta didik sangat antusias mengikutinya. Semua membaca dengan tenang dan tertib. Minat baca peserta didik sebenarnya sangatlah tinggi, ini dapat dilihat jika guru menyediakan bahan pustaka yang baru peserta didik berebut untuk membacanya.

Laporan tahunan yang dibuat oleh pengelola perpustakaan menjadi penting karena laporan tersebut merupakan alat yang dapat digunakan untuk melihat eksistensi perpustakaan. Dalam penelitian ini, penulis memperolah data laporan pengunjung perpustakaan selama 2 tahun ajaran terakhir adalah sebagai berikut :

Tabel 1

Laporan Pengunjung Perpustakaan SD Negeri Glagahombo 1 Tahun Ajaran 2017/2018

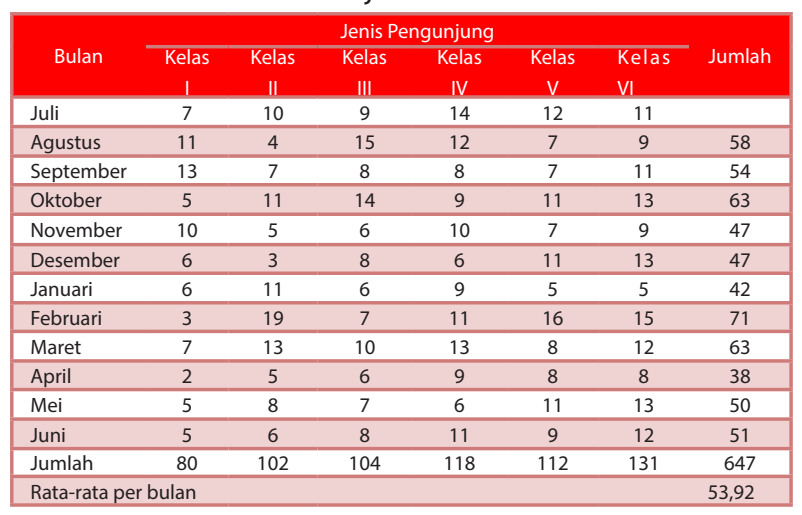

Sumber: Data Statistik SD Negeri Glagahombo 1 diolah
Tabel 2

Laporan Pengunjung Perpustakaan SD Negeri Glagahombo 1 Tahun Ajaran 2018/2019

\begin{tabular}{|c|c|c|c|c|c|c|c|}
\hline \multirow[b]{2}{*}{ Bulan } & \multicolumn{6}{|c|}{ Jenis Pengunjung } & \multirow[b]{2}{*}{ Jumlah } \\
\hline & Kelas & $\begin{array}{c}\text { Kelas } \\
\text { II }\end{array}$ & $\begin{array}{c}\text { Kelas } \\
\text { III }\end{array}$ & $\begin{array}{l}\text { Kelas } \\
\text { IV }\end{array}$ & Kelas V & Kelas VI & \\
\hline Juli & 6 & 4 & 5 & 5 & 7 & 11 & 38 \\
\hline Agustus & 5 & 7 & 11 & 5 & 6 & 8 & 42 \\
\hline September & 6 & 9 & 9 & 7 & 7 & 11 & 49 \\
\hline Oktober & 8 & 6 & 11 & 12 & 6 & 12 & 55 \\
\hline November & 7 & 10 & 6 & 6 & 8 & 9 & 46 \\
\hline Desember & 5 & 7 & 11 & 8 & 14 & 10 & 55 \\
\hline Januari & 6 & 8 & 7 & 5 & 11 & 6 & 43 \\
\hline Februari & 8 & 6 & 8 & 11 & 12 & 7 & 52 \\
\hline Maret & 5 & 12 & 10 & 7 & 9 & 11 & 54 \\
\hline April & 4 & 11 & 8 & 9 & 8 & 8 & 48 \\
\hline Mei & 7 & 7 & 11 & 9 & 10 & 8 & 52 \\
\hline & 6 & 5 & 5 & 9 & 6 & 8 & 39 \\
\hline Jumlah & 73 & 92 & 102 & 93 & 104 & 109 & 573 \\
\hline
\end{tabular}

Sumber: Data Statistik SD Negeri Glagahombo 1 diolah

Dari data Tabel 1 dan Tabel 2, terlihat bahwa adanya penurunan pengunjung perpustakaan dari tahun sebelumnya. Pada tahun 2017/2018 jumlah total pengunjung sebesar 647 orang dan tahaun 2018/2019 berjumlah 573 orang (turun 74 orang/12\%). Rata-rata pengunjung per bulan tahun 2017/2018 berjumlah 54 orang dan pada tahun 2018/2019 turun menjadi 48 orang. Hal ini tentunya akan berpengaruh dengan target perpustakaan dalam meningkatkan jumlah pengunjungnya. Dalam hal ini petugas perlu membuat jadwal wajib kunjung perpustakaan yang dimasukkan dalam kegiatan pembelajaran.

Selain laporan pengunjung perpustakaan, petugas perpustakaan juga membuat laporan peminjaman buku yang dilaporkan setiap bulan kepada kepala sekolah. Laporan peminjaman buku tersebut jika direkap dalam laporan tahunan 2 tahun terakhir adalah sebagai berikut:

Tabel 3

Laporan Peminjaman Buku Perpustakaan

SD Negeri Glagahombo 1

Tahun Ajaran 2017/2018 \& 2018/2019

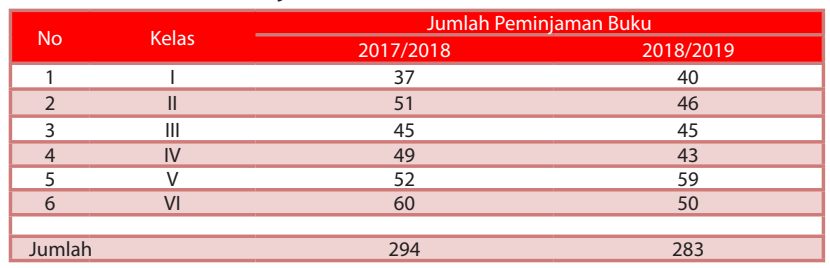

Sumber: Data Statistik SD Negeri Glagahombo 1 diolah 
Dari data peminjaman buku dapat dilihat pada Tabel 3, bahwa peminjaman buku belum maksimal. Buku yang kurang bervariasi adalah menjadi salah satu penyebabnya. Minimnya anggaran adalah menjadi penyebab perpustakaan sulit menambah koleksinya. Terlebih pada 3 tahun terakhir ini anggaran dana perpustakaan banyak dipergunakan untuk membeli buku pembelajaran karena adanya perubahan kurikulum pada sekolah.

Dalam wawancara yang penulis lakukan dengan petugas perpustakaan, petugas perpustakaan mengatakan bahwa pemilihan lokasi dari awalnya dibangun perpustakaan ini kurang tepat. Perpustakaan pada awal pembangunan terletak terlalu dekat dengan toilet peserta didik. Hal ini tentu akan membuat pengujung perpustakaan tidak nyaman. Kemudian pada tahun 2010 toilet peserta didik baru dipindahkan untuk menjaga kenyamanan pengunjung perpustakaan. Namun bukan hal itu saja yang menjadi kendala perpustakaan tidak berjalan dengan optimal. Tata letak, koleksi, dan sarana prasarana juga menjadi penyebab minimnya pengunjung. Dalam hal ini petugas perpustakaan mencoba mengajukan pemindahan tempat dan penambahan anggaran untuk penambahan koleksi dan sarana prasarana. Anggaran adalah merupakan unsur yang penting juga untuk diperhatikan. Tanpa adanya anggaran yang rutin dari sekolah, perpusatkaan tidak mungkin dapat dikelola dan dijalankan dengan baik. walaupun memiliki sistem ataupun tujuan yang bagus. Pengelola perpustakaan harus mampu membuat perancangan anggaran yang matang agar perpustakaan tetap berjalan walaupun dengan keterbatasan dana.

Untuk mengembangkan perpustakaan, sekolah tentunya harus mengalokasikan dana khusus untuk pengembangan dan perawatan perpustakaan. Dalam hal pengembangan, pengelola perpustakaan perlu memperhatikan dari segi koleksi, sarana dan prasarana, dan penataan ruang agar para pengguna betah berkunjung ke perpustakaan. Dari segi perawatan, pengelola perpustakan perlu memperhatikan dari perawatan meubeleir, gedung, dan koleksi. Alokasi dana sekolah untuk pengembangan perpustakaan yang sangat minim yaitu 5\% dari alokasi dana BOS dinilai masih sangat minim untuk memenuhi semua aspek tersebut.

Dengan minimnya anggaran yang diperoleh perpustakaan untuk pengembangan dan perawatan, pengelola perpustakaan harus lebih kreatif dalam menggali sumber dana. Sumber dana dapat didapatkan dari berbagai macam cara tanpa memberatkan peserta didik diantaranya dengan cara : menyelenggarakan sumbangan sukarela dari orang tua/wali peserta didik, penarikan denda kepada peserta didik yang telat mengembalikan buku, memperbaiki buku yang rusak saat dipinjam, dan sebagainya. Masih banyak yang perlu dipikirkan oleh pengelola perpustakaan agar perpustakaan bisa lebih maju dan berkembang.

Peneliti Ling Hin Li, Fan Wu dan Boya Su (2018) dalam riset berjudul Dampak Ruang Perpustakaan pada Kepuasan Belajar - Studi Empiris Desain Perpustakaan Universitas di Guangzhou, Cina menjelaskan bahwa generasi mahasiswa milenium saat ini lebih terbiasa mencari informasi referensi online daripada mengunjungi fasilitas perpustakaan fisik, dibandingkan dengan generasi mahasiswa sebelumnya. Penelitian telah menunjukkan bahwa peran fasilitas perpustakaan fisik sebagai titik pengumpulan bahan bacaan dan referensi sedang terancam oleh ketersediaan mesin pencari online gratis dan berkecepatan tinggi. Perpustakaan universitas selalu menjadi bagian integral dalam kegiatan pembelajaran pendidikan tinggi, dan mereka tidak dikecualikan dari ancaman ini. Berdasarkan kerangka pemodelan persamaan struktural, kami menganalisis secara empiris pentingnya fitur desain perpustakaan yang berbeda yang membantu meningkatkan 
kepuasan belajar siswa, dan menemukan bahwa lingkungan pencahayaan, lingkungan akustik serta lokasi gedung perpustakaan adalah penentu utama yang berdampak pada penggunaan. perpustakaan universitas oleh siswa di sebuah universitas besar di Cina. Kami menyimpulkan makalah dengan saran kami dalam memodifikasi desain perpustakaan untuk mengakomodasi kebutuhan belajar siswa, dan yang lebih penting dalam merekonstruksi peran spasial dan fungsional perpustakaan universitas di era ini informasi digital dari penyedia bahan referensi belaka ke ruang fisik belajar bersama di kampus.

Hasil penelitian Reza Askariza dan Hossein Safari (2019) berjudul Investigasi peran ruang semi-terbuka pada sosialisasi perpustakaan umum menggunakan sintaksis ruang (Studi Kasus: Sunrise Mountain dan Desert Broom Libraries, Arizona, USA) menjelaskan saat ini, terlepas dari upaya positif yang dilakukan dalam beberapa tahun terakhir, perpustakaan umum yang aktif masih menghadapi tantangan dalam menarik dan mempertahankan penggunanya melalui penyediaan layanan terbaru untuk memenuhi persyaratan ilmiah, budaya, dan rekreasi mereka. Dengan demikian, kebutuhan untuk menciptakan ruang dengan pendekatan sosialisasi di perpustakaan umum tampaknya diperlukan. Dengan cara ini, metode Space Syntax, sebagai prediktor aspek sosial ruang arsitektur, telah digunakan untuk mengevaluasi peran ruang semi-terbuka pada kemampuan bersosialisasi perpustakaan umum dalam model yang ada dan hipotesis menggunakan Depthmap. Akhirnya, temuan dari dua model simulasi diperiksa dan dibandingkan satu sama lain menggunakan SPSS dan independent sample t-test. Temuan dari analisis Sunrise Mountain Library menunjukkan bahwa dalam model yang ada, tingkat integrasi adalah 20,49. Namun, setelah menghilangkan ruang semi-terbuka, tingkat integrasi menurun menjadi 15,48 . Juga, temuan yang diperoleh dari
Perpustakaan Desert Broom menunjukkan bahwa dalam model yang ada, tingkat integrasi adalah 10,10. Namun, dalam model hipotesis, tingkat integrasi berubah menjadi 8,15. Hasil menunjukkan bahwa ruang semi-terbuka memiliki efek positif pada sosialisasi perpustakaan umum.

\section{PENUTUP}

\section{Simpulan}

Berdasarkan hasil penelitian dapat disimpulkan bahwa:

1. Minat baca peserta didik sangatlah tinggi.

2. Letak gedung perpustakaan yang terlalu jauh dengan pusat kegiatan peserta didik merupakan faktor utama peserta didik malas berkunjung ke perpustakaan.

3. Bangunan perpustakaan masih sangat sederhana sekali hampir tidak bisa dibedakan dengan gedung lainnya.

4. Pengelola perpustakaan yang diberi tugas lain menjadikan perpustakaan sekolah ini beroperasi tidak maksimal.

5. Anggaran yang sangat minim menjadikan perpustakaan sekolah ini sulit untuk berkembang.

\section{Saran}

Setelah melakukan penelitian, dengan ini penulis menyampaikan saran-saran sebagai berikut:

1. Minat baca peserta didik yang sudah tinggi hendaknya didukung dengan koleksi bacaan yang memadai dan pemberian motivasi agar minat baca peserta didik tidak hilang.

2. Jika memungkinkan gedung perpustkaan sebaiknya dipindah ke depan mengingat ada ruang di depan yang tidak terpakai dan cukup luas jika dialihfungsikan menjadi gedung perpustakaan.

3. Bangunan perpustakaan sebaiknya dibuat berbeda atau lebih mencolok daripada bangunan lainnya. 
4. Pengelola perpustakaan hendaknya fokus dengan satu pekerjaannya yaitu mengelola dan mengembangkan perpustakaan, tugas yang diemban selain yang berkaitan dengan pengelolaan perpustkaan dapat dilimpahkan ke guru/staf lain yang dinilai berkompeten dan mampu menggantikan tugasnya.

5. Perlu adanya anggaran lain di luar anggaran $5 \%$ dari dana BOS yang sebaiknya dibicaran dengan warga sekolah dan melibatkan komite sekolah.

\section{DAFTAR PUSTAKA}

Askariza, Reza \& Safari, Hossein. 2019. Investigating the role of semi-open spaces on the sociability of public libraries using space syntax (Case Studies: Sunrise Mountain and Desert Broom Libraries, Arizona, USA). Ain Shams Engineering Journal Available online 25 October 2019.

Hartinah, Sri. 2014. Metode Penelitian Perpustakaan. Tangerang Selatan: Universitas Terbuka.

Ling Hin Li, Fan Wu \& Boya Su. 2018. Impacts of Library Space on Learning Satisfaction - An Empirical Study of University Library Design in Guangzhou, China. The Journal of Academic Librarianship Volume 44, Issue 6, November 2018, Pages 724-737.

Sulistyo-Basuki. 2010. Pengantar Ilmu perpustakaan. Jakarta: Universitas Terbuka. 